\title{
A Survey of the Dictionary Use of Gabonese Students at Two South African Universities*
}

\author{
Guy-Modeste Ekwa Ebanéga (guymodeste_e@yahoo.fr) \\ and \\ Fatima Tomba Moussavou (tombafatima@yahoo.fr), \\ Department of Afrikaans and Dutch, University of Stellenbosch, Stellenbosch, \\ Republic of South Africa
}

\begin{abstract}
This article presents a preliminary study on Gabonese users' knowledge, opinions, attitudes and habits of the use of dictionaries, and their dictionary culture. It is based on the principle that the lexicographer should know the target users and their needs (Householder and Saporta 1962: 279). The aim of the article is to present and discuss research findings of a lexicographic survey conducted among 100 Gabonese students at the University of Stellenbosch and the Cape Peninsula University of Technology with regard to dictionary use and culture. In this article, we discuss the objective of the research, the research subjects, the research methods, the research coverage, the research findings, the description and the critical analysis of the data.
\end{abstract}

Keywords: SURVEY, QUESTIONNAIRE, GABONESE USERS, DICTIONARY CULTURE, NEEDS

Résumé: Une enquête de l'utilisation du dictionnaire des étudiants gabonais à deux universités sud-africaines. Cet article présente une étude préliminaire sur la connaissance des utilisateurs gabonais, leurs avis, leurs attitudes et leurs habitudes de l'utilisation des dictionnaires, et leur culture de dictionnaire. Il est basé sur le principe selon lequel le lexicographe devrait connaître les usagers cibles et leurs besoins (Householder et Saporta 1962: 279). Le but de l'article est de présenter et discuter des résultats de recherches d'une enquête lexicographique conduite parmi 100 étudiants gabonais à l'Université de Stellenbosch et à l'Université Cape Peninsula de Technologie en ce qui concerne l'utilisation et la culture du dictionnaire. Dans cet article nous discutons l'objectif de la recherche, les informants, les méthodes de la recherche, l'assurance de la recherche, les résultats de la recherche, la description et l'analyse critique des données.

Mots-clés: ENQUÊTE, QUESTIONNAIRE, USAGERS GABONAIS, CULTURE DU DICTIONNAIRE, BESOINS

This article is an adapted version of a paper presented at the Eleventh International Conference of the African Association for Lexicography, organized by the Tshivenda National Lexicography Unit, University of Venda for Science and Technology, Thohoyandou, Republic of South Africa, 5-7 July 2006. 


\section{Introduction}

Lexicographically speaking, three periods characterize Gabonese lexicography. The first is the missionary period, followed by the colonial period and eventually the modern period. The first and the second are the periods of the missionaries and the colonial administrators. They are the pioneers in the compilation of dictionaries in the Gabonese languages, which are all bilingual (or translation) dictionaries biased towards French and aimed at foreign users, the French speakers. The third is the modern period when national lexicographers trained in metalexicographical principles started compiling dictionaries aimed at the Gabonese users.

This article describes and discusses a preliminary survey on Gabonese users' knowledge of, opinions about, attitudes towards and habits regarding the use of dictionaries, and their dictionary culture. Most studies of dictionary use have therefore relied on the retrospection of users by means of questionnaires or interviews (for example Tomasczyk 1979, Béjoint 1981, Bogaards 1988, and Atkins and Varantola 1998).

This article is based on the premise that lexicographers should know the target users and their needs (Householder and Saporta 1962: 279).

The aim of this article is to present and discuss research findings of a lexicographic survey conducted among 100 Gabonese students at the University of Stellenbosch and the Cape Peninsula University of Technology with regard to dictionary use, their dictionary culture.

\section{Problem statement}

Hartmann (1989), Gouws (1989) and Wiegand (1998) emphasize an approach of compiling dictionaries guided by the user-perspective. The user-perspective, so prevalent in modern-day metalexicography, compels lexicographers to compile their dictionaries according to the needs and research skills of well-defined target user groups. Hartmann (1989) aptly indicates that the compilation of any new dictionary has to be preceded by an in-depth needs analysis. This analysis can only be done once the intended target users have been identified unambiguously. It should reflect not only the needs but also the reference skills of the target users. An analysis of users' needs should precede dictionary design. According to Gouws and Prinsloo (2005: 39), good dictionaries do not only display a linguistically sound treatment of a specific selection of items. They are products that can be used as linguistic instruments by their respective target user groups.

According to Tarp (2002: 67), the starting point when planning, compiling or reviewing a dictionary should always be the users, the user situations and the complex of problems related to these situations which could finally cause the user to consult a dictionary for assistance. Householder and Saporta (1962: 279) emphasize that 'dictionaries should be designed with a special set of users 
in mind and their specific needs'. This stresses the importance of understanding the needs of the dictionary users before compiling a dictionary.

For De Schryver and Prinsloo (2000: 1-31), the feedback from the users should be obtained while the compilation of the dictionary is still in progress, a process referred to as 'simultaneous feedback'. Atkins and Varantola (1998) and Bogaards (1998) are good examples of the serious efforts currently being made to research dictionary use. The problem however is that such research is generally carried out at a stage when dictionaries are already completed and published. Feedback from target users can therefore only be implemented in forthcoming editions of these dictionaries.

Up to now, no survey or empirical research has been done to establish the profile of Gabonese people as dictionary users. The statement of Whitcut (1986: 111) 'we know who we are, but who are they?' is still valid today and particularly in the Gabonese environment.

\section{Objective of the research}

The main purpose of this research, which was carried out during the academic year 2005-2006, was to draw a profile of Gabonese students as dictionary users. Indeed, the intention was to ascertain their knowledge about, opinions on, and habits in the use of dictionaries. The general goals were the following:

- To gather information about the dictionary users (the frequency of their use of dictionaries, their difficulties with the lookup process and the causes of these difficulties, the instruction they received to acquire dictionary skills, etc.)

- To find out the users' attitude towards different reference books (general dictionaries, bilingual dictionaries, encyclopaedic dictionaries, etc.)

- To know with which type of dictionary to start if dictionaries are to be compiled in the Gabonese languages.

\section{Research subjects}

The survey was carried out among 100 undergraduate and postgraduate Gabonese students, who are studying at the University of Stellenbosch and the Cape Peninsula University of Technology. These students came to study in the Western Cape under the convention between Gabonese universities and South African universities. Many Gabonese also study abroad, particularly in France, at university and graduate levels.

Because of money constraints, the investigation was undertaken only among Gabonese students in South Africa. The behaviour of Gabonese dictionary users studying in Gabon, for example at the Omar Bongo University, Libreville, and the University of Science and Technology of Masuku, near 
Franceville, could therefore not be examined. For the purpose of this survey, the students were asked some personal information such as their gender, their age, their course of study, their degree, and their study subjects. Enquiries were also made about the language they mainly speak at home, the foreign languages they have studied and their ability to write in their home language. The participants in this survey were 36 females and 64 males with ages varying between 19 and 35 years.

- Most Gabonese students have different mother-tongue backgrounds. The distribution of the mother-tongue speakers is as follows:

$\begin{array}{llll}\text { Fang: } 29 & \text { Lembaama: } 7 & \text { Myene: } 4 & \text { Tsogho: } 1 \\ \text { French: } 26 & \text { Yinzebi: } 5 & \text { Lekanighi: } 2 & \text { Teke: } 2 \\ \text { Yipunu: } 5 & \text { Awandji: } 1 & \text { Mbebe: } 1 & \text { Lumbu: } 1 \\ \text { Mahongwe: } 1 & \text { Bemba: } 1 & \text { Ghisira: } 1 & \text { Aduma: } 3 \\ \text { Ndumu: } 2 & \text { Obamba: } 4 & \text { Civili: } 1 & \text { Ikota: } 3\end{array}$

74 of the students state that they have Gabonese languages as mother tongue. This is due to the fact that some Gabonese languages (Fang, Myene, Yipunu and Yinzebi) have the status of vehicular languages on a regional level, while other vehicular languages are domestic languages (cf. Idiata 2005). 26 of the students claim to have French as mother tongue, which results from the status of French in Gabon. In fact, the Gabonese languages co-exist with French, which is the only official language. French in Gabon is the language of knowledge and science, the language of power and rights, the language which ensures social and professional promotion (Mba-Nkoghe 1981: 23).

- Most Gabonese students had European languages as subjects. The distribution of the data is as follows:

$\begin{array}{llll}\text { French: } 80 & \text { Italian: } 5 & \text { Spanish: 39 } & \text { Mandin: 1 } \\ \text { English: } 74 & \text { Portuguese: } 3 & \text { German: } 5 & \text { Latin: 2 }\end{array}$

From the results of the questionnaire, it may seem that Gabonese languages cannot be taken as subjects. However, this is not the case as the use of the Gabonese languages today is the result of the radical innovation in the educational language policy. In Gabon, particularly in Libreville, some secondary schools offer some Gabonese languages as subjects. This could be extended to primary schools, universities and to other educational institutions in Gabon.

- The Gabonese students were asked to list the languages they mainly speak at home. The distribution of the data is as follows:

$\begin{array}{llll}\text { Fang: } 11 & \text { Lekanighi: } 2 & \text { Yipunu: } 2 & \text { Ikota: } 1 \\ \text { French: } 82 & \text { Yinzebi: } 3 & \text { Lumbu: } 1 & \text { Lembaama: } 1 \\ \text { Tsogho: } 1 & \text { Awandji: } 1 & & \end{array}$


The majority of Gabonese students have studied French and mainly speak French at home. This is due to the privileged position and the official status of French in Gabon.

- The subjects studied by the Gabonese students at their respective universities are the following:

$\begin{array}{lll}\text { Lexicography: } 6 & \text { Business Management: } 22 & \text { Biotechnology: } 5 \\ \text { Geology: } 5 & \text { Conservation Ecology: } 5 & \text { Sociology: } 1 \\ \text { Forestry: } 3 & \text { Phonetics: } 1 & \text { Marketing: } 3 \\ \text { English: } 26 & \text { Mechanical Engineering: } 4 & \text { Mathematics: } 2 \\ \text { History: } 2 & \text { Food Science: } 1 & \text { Biochemistry: } 1 \\ \text { Medical Science: } 1 & \text { Architecture: } 1 & \text { Economics: } 1 \\ \text { Botany: } 2 & \text { Zoology: } 1 & \text { Physiology: } 1 \\ \text { Food Science: } 1 & \text { Environmental Health: } 1 & \end{array}$

- The question about the ability of the Gabonese students to write their mother tongues was answered as follows:

Yes: $48 \%$

No: $52 \%$

As more than $50 \%$ of the Gabonese students cannot write their mother tongues, there is a need for learning to write the Gabonese languages. A dictionary serving as an example could be a solution to this. The function of dictionaries in text production should be taught to students. Compilers of future dictionaries in the Gabonese languages should be responsible for promoting the orthography of the Gabonese languages considered as standard or accepted by the majority of Gabonese language users in order to write efficiently in these languages.

\section{Research methods}

A questionnaire comprising 22 questions was given to all subjects. This questionnaire, based on the one developed by Hartmann (1999), was adapted for Gabonese users. Though different in objective, the method is comparable to that employed by Nesi and Haill (2002) who investigated the dictionary-using habits of international students studying through the medium of English at a British university.

\section{Research coverage}

The questionnaire given to participants in the survey dealt with the following 22 items:

(1) First use and acquisition of a dictionary

(2) Types of dictionaries owned 
(3) Number of dictionaries owned

(4) Knowledge and use of electronic dictionaries

(5) Types of dictionaries existing in the Gabonese languages

(6) Types of dictionaries most frequently used in Gabon

(7) Type of dictionary first to be compiled in the Gabonese languages

(8) Type prioritized when buying a new dictionary

(9) Reason for the last acquisition of a dictionary

(10) Circumstances under which a dictionary is used

(11) Reasons for using a dictionary

(12) Frequency of using dictionaries

(13) Use of information in the appendices of dictionaries

(14) Awareness of the user guide notes in the front matter of dictionaries

(15) Ability to find the information needed in a dictionary

(16) Type of information the most difficult to find in dictionaries

(17) Causes for difficulties in finding information in dictionaries

(18) Satisfaction with the ability to use a dictionary

(19) Opinions regarding the use of a dictionary

(20) Attitudes towards the use of dictionaries

(21) Instruction in dictionary use

(22) Importance of being taught to use a dictionary

\section{Research findings, description and analysis of the data}

\subsection{When did you start using and when did you acquire a dictionary?}

$61 \%$ and $58 \%$ of Gabonese students claimed to have started using and to have acquired a dictionary at primary school, $26 \%$ and $37 \%$ at secondary school and $0 \%$ and $2 \%$ at university.

This is an important question because it indicates when there should be started with teaching the use of dictionaries. Dictionaries are introduced at primary school in Gabon. Therefore, instruction in dictionary use should also start at this stage.

\subsection{What types of dictionaries do you own?}

The following were specified:

General dictionary (e.g. Dictionary of English): 85\%

Special subject dictionary (e.g. Dictionary of Music): $18 \%$

Bilingual dictionary (e.g. English-French Dictionary): $81 \%$

Thesaurus (e.g. Dictionary of Synonyms): 36\%

Encyclopaedia: $46 \%$

Gabonese students are very familiar with monolingual and bilingual dictionaries, but unfamiliar with special subject dictionaries. Dictionary typology explaining the main dictionary types should be taught at primary school. 


\subsection{How many dictionaries do you own?}

19 students claimed to have 4 dictionaries

26 students claimed to have 3 dictionaries

27 students claimed to have 2 dictionaries

6 students claimed to have 1 dictionary

72 students have more than one dictionary, with only 6 saying that they own 1 dictionary. These results indicate that on the whole Gabonese students are dictionary knowledgeable.

\subsection{Do you own any electronic dictionaries?}

$$
\text { Yes: } 21 \% \quad \text { No: } 78 \%
$$

As only a small number of Gabonese students own any electronic dictionaries, an introduction to electronic dictionaries and their use should be taught at school.

\subsection{Which dictionary type(s) exist in the Gabonese languages?}

The results indicating the answers to this question are as follows:

General dictionary (e.g. Dictionary of French): 36\%

Special subject dictionary (e.g. Dictionary of Music): $10 \%$

Bilingual dictionary (e.g. English-French Dictionary): $46 \%$

Thesaurus (e.g. Dictionary of Synonyms): $38 \%$

Encyclopaedia: $46 \%$

As has already been stated above, the only type of dictionary existing in the Gabonese languages are bilingual dictionaries. Different answers given by students show that some do not know which specific dictionaries are available in the Gabonese languages. These results prove that Gabonese students have mostly been introduced to French dictionaries.

Existing dictionaries in the Gabonese languages are mainly unknown to the students. A course in the history of Gabonese lexicography, aiming to make known the available dictionaries in the Gabonese languages, should be taught at school.

\subsection{Which dictionary type(s) do you use most frequently in Gabon?}

The percentages obtained to this question are the following:

General dictionary (e.g. Dictionary of French): 79\%

Special subject dictionary (e.g. Dictionary of Music): $9 \%$ 
Bilingual dictionary (e.g. English-French Dictionary): 63\%

Thesaurus (e.g. Dictionary of Synonyms): $36 \%$

Encyclopaedia: $67 \%$

This shows that most students prefer a general dictionary, followed by an encyclopaedia and a bilingual dictionary, and then a thesaurus, with only a small percentage selecting a special subject dictionary. Gabonese students are mostly using general dictionaries, encyclopaedias and bilingual dictionaries in French, the official language of Gabon. There is certainly a dictionary culture as far as French is concerned. Referring to Hausmann (1989: 13), Gouws and Prinsloo (2005: 12) stress that:

A dictionary culture implies that the members of a given speech community are familiar with different types of dictionaries and with the contents and presentation of these dictionaries. It also implies that they have reached a certain level of dictionary using skills. These skills do not come instinctively but need to be acquired.

The observation of Nyangone Assam and Mavoungou (2000: 226) is still valid: 'As far as the lexicographic needs of Gabonese languages are concerned, there is a lack of a dictionary culture.'

\subsection{Which type of dictionary should first be compiled in the Gabonese languages?}

The following results were obtained:

General dictionary (e.g. Dictionary of French): $32 \%$

Special subject dictionary (e.g. Dictionary of Music): $2 \%$

Bilingual dictionary (e.g. English-French Dictionary ): 64\%

Thesaurus (e.g. Dictionary of Synonyms): 17\%

Encyclopaedia: $12 \%$

Most students show a preference for a bilingual dictionary, then a general dictionary, followed by a thesaurus and encyclopaedia, and lastly a special subject dictionary.

The compilation of dictionaries in the Gabonese languages should start with bilingual ones. In Gabon where most of the languages are developing languages, bilingual dictionaries are seriously needed. As the Gabonese languages lack a solid lexicographic tradition, studying aspects of English and French lexicography as examples is inevitable. Problems of dictionary use in English and French could be regarded as a way of approaching problems likely to occur in the Gabonese languages. In this regard Mickala Manfoumbi (2004) took the courageous step of publishing the Lexique pové-français/français-pové, a bidirectional lexicon of one of the minority languages in Gabon. Future bilingual dictionaries of the Gabonese languages need to be planned carefully in order to meet the needs of Gabonese dictionary users. 


\subsection{What is your priority when buying a new dictionary?}

Its relevance to your needs: $90 \%$

The number of words: $12 \%$

The number of examples: $10 \%$

A reasonable price: $12 \%$

The reputation of the publisher: $16 \%$

Finding it convenient to be carried about: $3 \%$

An overwhelming percentage of the Gabonese students indicated that they were led by their needs when deciding on which dictionary to buy. The standing of the publisher together with the number of words and examples and an affordable price received a much lower percentage. Gabonese students are aware that dictionaries are made to satisfy or respond to users' needs.

\subsection{When you last bought a dictionary, was it ...?}

because a teacher or tutor recommended it: $23 \%$

because a friend or relative suggested it: $7 \%$

as a result of your own deliberate choice: $69 \%$

as a result of an advertisement: $0 \%$

due to an impulse: $8 \%$

I cannot remember: $3 \%$

Most Gabonese students (69\%) indicated that they made their own decision when buying a dictionary, while a much smaller number (23\%) stated that they were influenced by the advice of a teacher or tutor.

To help students and teachers to come to a satisfactory decision when buying a dictionary, Gabonese lexicographers and booksellers should make useful information about dictionaries available, such as:

- The age of the user: It should be ascertained whether the dictionary is suitable for children, adolescents or adults.

- The function of the dictionary: It should be checked whether it is a monolingual or a bilingual dictionary, meant for text production or text reception, for mother-tongue speakers or learners, etc.

- The language used in the dictionary: The task of the compilers of dictionaries is to record the way the language is used. The dictionary should have included new words and expressions.

- $\quad$ The number of lemmas (headwords), i.e. the number of words defined in the dictionary: The user will nearly always be given this information on the cover. 
- The language of the definitions: Users need to have a close look at the nature of the definitions and the words used in the definitions. Good dictionaries ensure that definitions are easy to understand, and that difficult words in the definition can also be found in the dictionary.

- The amount of information given in each entry: Grammatical information, pronunciation, spelling, etymology, example sentences, etc. should be included in the dictionary.

- Illustrations: Research has shown that illustrations do not necessarily help users (especially children) acquire vocabulary or understand meanings, although they do add to the visual appeal and 'brighten' the text.

- Ease of reading and use: The user must consider features such as the legibility of the typeface, the layout of the entries, and appendices such as spelling rules, common abbreviations, weight and measures, foreign phrases, and countries of the world, which can be useful additional information.

\subsection{When do you use a dictionary?}

During class: $20 \%$

During an examination: $4 \%$

While studying at home: $91 \%$

While studying in a library: 59\%

Other (specify): $14 \%$

The majority of Gabonese students (91\%) make use of dictionaries when studying at home, and a lesser number (59\%) when studying in a library. Only $20 \%$ use a dictionary during class and a small $40 \%$ use dictionaries during an examination. Allowance should also be made for students to use dictionaries during examinations.

\subsection{Do you use a dictionary while you ...?}

read newspapers and magazines: $47 \%$ read textbooks: $65 \%$

read academic journals: $44 \%$

read a book for entertainment: $27 \%$

work on a translation exercise: $75 \%$

play word games: $45 \%$

Almost three-quarters of the students use dictionaries while they work on a translation exercise or read textbooks. Nearly the same number use dictionaries when reading newspapers, magazines and academic journals. This is also the 
case when they do crosswords and play word games, which shows that these activities encourage Gabonese students' use of dictionaries and improve their dictionary skills.

\subsection{Do you use a dictionary ...?}

when you write: $63 \%$

when you read: $67 \%$

when you listen: $20 \%$

when you speak: $1 \%$

to look up a definition/equivalent of a word: $74 \%$

to look up the spelling of a word: $58 \%$

to look up synonyms/words of a similar meaning: $46 \%$

to look up examples of a word's use: $37 \%$

to look up a grammar point, e.g. part of speech: $20 \%$

to look up encyclopaedic information: $13 \%$

to look up the pronunciation: $41 \%$

Most Gabonese students use a dictionary for finding the meaning of a word, followed by information on spelling, synonyms, pronunciation, usage, and grammar. Only a small number look for encyclopaedic information. Gabonese students use dictionaries for communicative purposes, i.e. encoding or decoding purposes: $63 \%$ when they write, $67 \%$ when they read. The importance of each data type should be emphasized in the teaching of dictionary use, particularly encyclopaedic information.

\subsection{Do you ever use information contained in the appendices?}

The students were exposed to a list of options including the most common information appendices found in different dictionaries. The percentages for the different appendices indicated were as follows:

List of abbreviations: $57 \%$

List of regular/irregular verbs: $73 \%$

Proper names : $26 \%$

Units of measurement: $21 \%$

Other: $12 \%$

From the above results, it becomes clear that students should be taught the structures of the dictionary, particularly the frame structure, consisting of the central list (the dictionary proper), the front matter (all functional text parts preceding the central list) and the back matter (texts coming after the central list) and how to retrieve the maximum information from this variety of texts. 
6.14 If you are aware of the user guide notes in the front matter of the dictionary, do you ...?

study them: $24 \%$

find them user-friendly: $31 \%$

manage without them: $40 \%$

These results show that $40 \%$ of the students ignore the information in the user guide notes, which is not very encouraging when it is considered that these provide useful information (such as the organization of the dictionary, an explanation of the pronunciation, etc.). Familiarity with the user guides could produce an immediate effect in both understanding and reducing the lookup process. The importance of the user guide notes should be taught to students.

\subsection{Do you ever consult a dictionary without being able to find the infor-} mation you need?
Very often: $4 \%$
Often: $11 \%$
Sometimes: $76 \%$
Never: $10 \%$

A large percentage of Gabonese students sometimes do not find the information they need. It is important to teach students how to obtain the required information.

\subsection{What type of information is most difficult to find?}

The percentages of the answers to this question are as follows:

General words: $2 \%$

Specialized technical terms: $75 \%$

Common words in a special subject area: $34 \%$

Idioms, proverbs, phrases: $26 \%$

Three-quarters of the Gabonese students selected specialized technical terms as the most difficult type of information to find. Just over one-third of the students and just under one-third of the students also indicated that they have difficulties with special subject terms and idioms, proverbs and phrases respectively. Gabonese students particularly need help on how to trace specialized technical terms in a dictionary.

\subsection{What do you think are the causes of these difficulties?}

My lack of dictionary skills: $13 \%$

My lack of dictionary knowledge: $7 \%$

Not enough information in the dictionary: 63\% 
The unclear layout of the dictionary: $22 \%$

Because I do not read the instructions to the user: $13 \%$

Gabonese students attributed the greatest part of their difficulties to the dictionary itself. In fact, the students believe that these problems are mainly the result of there not being enough information in the dictionary, while others related these problems to the unclear layout of the dictionary, a lack of dictionary skills, not reading the user instructions and a lack of dictionary knowledge were also seen as factors causing difficulties. From a user point of view, the importance of dictionary skills needs to be taught to the users to avoid difficulties in dictionary consultation.

\subsection{Are you on the whole satisfied with your ability to use a dictionary?}

Yes: $81 \%$

No: $19 \%$

Four-fifths of the Gabonese students are satisfied with their ability to use a dictionary, while one-fifth feel that they have to acquire more dictionary skills.

\subsection{In your opinion, using dictionaries is ...}

easy: $48 \%$

difficult: $3 \%$

exciting/fun: $24 \%$ tedious/boring: $3 \%$

worthwhile/informative: $58 \%$

of little help/not worth the trouble: $2 \%$

Except finding the use of dictionaries worthwhile and informative (almost $60 \%$ ), Gabonese students also consider the consultation process easy (almost $50 \%$ ). This indicates that Gabonese students are familiar with dictionaries, also showing an awareness that dictionaries have a knowledge-orientated function.

\subsection{Based on your experience, with which of the following statements do you agree?}

Using dictionaries can improve my reading: $38 \%$

Using dictionaries can improve my writing: $66 \%$

Using dictionaries can help my speaking: $43 \%$

Using dictionaries can help me perform better in my studies: 53\%

About two-thirds of the Gabonese students state that using dictionaries can improve their writing, followed by about half who think that using dictionaries can help them perform better in their studies. Slightly less than half of the students think that using dictionaries can improve their reading and their speaking. Functions of dictionaries in text production and in text reception should be taught to students. 


\subsection{Have you ever been taught how to use a dictionary in Gabon?}

$$
\text { Yes: } 32 \% \quad \text { A little: } 38 \% \quad \text { Never: } 27 \%
$$

As can be seen from these answers, almost 30\% has never been instructed in dictionary use and almost $40 \%$ only slightly. These results show that teachers should insist more on the importance of the teaching of dictionary use in Gabon.

\subsection{Do you think it is important for students in Gabon to be taught how to use dictionaries?}

It is very important: $64 \% \quad$ It is important: $25 \%$

It is not important: $0 \% \quad$ I do not know: $7 \%$

Most Gabonese students (89\%) think it is very important or important to be taught how to use dictionaries. As has already been stated, there is a need for user education in Gabon, especially for teacher training.

User education is defined by Hartmann and James (1998: 152) as 'the training of users in the reference skills in response to reference needs'. Reference skills are 'the abilities required on the part of the dictionary user to find the information being sought' (Hartmann and James 1998: 117), while reference needs are 'the circumstances that drive individuals to seek information in reference works such as dictionaries' (Hartmann and James 1998: 116). It should be agreed with Hadebe (2004: 90) that 'by training teachers to be good users themselves, it is envisaged that they could pass these skills on to students and eventually to society in general'.

With reference to the foregoing discussion, the choice of focusing on teacher training is justified. To improve the lexicographic situation in Gabon in general, Ekwa Ebanéga (2007) points out that the teaching of reference skills should first target the teachers themselves, for example those at the ENS (École Normale Supérieure) and the ENI (École Nationale des Instituteurs). Teachers should be taught reference skills as part of their training in order to enable them to make maximum use of dictionaries and reference books and impart this knowledge to students in high school. Teachers are in a better position than researchers or even lexicographers to assess the students' lexicographic needs. If teachers acquire dictionary skills and pass on these skills to students, a dictionary culture could develop in the community.

To introduce dictionaries and dictionary using skills (for example to teachers), Gouws (1996: 107) suggests that non-government organisations could be employed to give new and other literates access to dictionary culture. Dictionaries are compiled by lexicographers but produced and distributed by publishers and booksellers who should have the necessary expertise. Their assignment 
is not only to make the dictionaries available but also to provide information on their optimal use. Publishing houses should co-operate with lexicographers and metalexicographers. Lexicographic planning for the Gabonese languages should take cognisance of these suggestions by Gouws.

Another approach to improve dictionary skills is the teaching of aspects of lexicography. Teachers should be initiated into the use of reference works of different types, dictionaries, thesauri and encyclopaedias, and others should receive basic training in dictionary structure, dictionary typology, lexicographic data (grammatical data, spelling, pronunciation, meaning, vocabulary etc.). There is also the need for teaching according to the level (beginner-intermediate-advanced) of their students.

In addition to the foregoing, teachers should be introduced into the history of the lexicography of the African languages in general and the Gabonese languages in particular. Missionaries and colonial administrators were the first who compiled dictionaries in the Gabonese languages. Similar examples have been observed in other African countries (cf. Mpofu 2001: 244, Mavoungou 2001: 123 and Hadebe 2004). Furthermore, teachers have to explain to users the motivations of the existing dictionaries. For example, with regard to external motivation, teachers could state that existing dictionaries in the Gabonese languages were not directed at specific speakers of these languages. As far as internal motivation is concerned, teachers could explain to users whether the dictionary is directed at promoting language or focusing on linguistic issues. For example, with regard to existing dictionaries in the Gabonese languages, teachers could explain to users the aim of these dictionaries. Knowing the history of the lexicography of the Gabonese languages (types of existing dictionaries, their different motivations, etc.) will help users to appreciate their own reference works.

\section{Conclusion}

The research discussed in this article has presented the viewpoints on dictionaries of a number of Gabonese students. Gabonese students start using and acquiring dictionaries in primary school. They most frequently use printed monolingual and bilingual dictionaries. They are less familiar with special subject dictionaries and electronic dictionaries. When they buy a new dictionary their priority is its relevance to their needs. They use a dictionary when they study at home and while they do translation exercises and read textbooks. They do not consult a dictionary in search of encyclopaedic or etymological information, but for the definition or equivalent of a word, the part of speech, pronunciation, spelling, synonyms, idioms or proverbs, and example sentences. For them, special technical terms are the most difficult information types to find in a dictionary. In their opinion, using dictionaries are easy and informative, can improve their reading, speaking and writing, and help them perform better in their studies. There is a dictionary culture as far as French is con- 
cerned, but there is a lack of a dictionary culture with regard to the Gabonese languages. Gabonese language dictionaries compiled by missionaries and colonial administrators should be known by and accessible to users. Bilingual dictionaries for text production and/or text reception aimed at Gabonese users should be the first to be compiled in order to establish a dictionary culture in the Gabonese languages.

The use of Gabonese language dictionaries presupposes that the student knows the alphabetical ordering principle of the dictionary and is acquainted with the use of keywords at the top of the pages. It also presupposes a basic knowledge of the grammatical structure of the language. Mother-tongue education is needed and required for the use of Gabonese language dictionaries.

The importance of instruction in dictionary use is not underestimated by Gabonese students. It is important for them to be taught how to use a dictionary, how to find the required information, and how to retrieve the maximal information in the variety of texts contained in a dictionary (front matter, central list, back matter). They want to be taught the functions of dictionaries (text production or text reception), to be shown the importance of the user guide notes, to be made aware of the variety of dictionaries available and the differences between them, and to be guided to choose the most suitable one when buying a dictionary. Similarly, Gabonese teachers should be taught how to use a dictionary. As far as Gabonese users are concerned, instruction in dictionary use should be given at primary level and continued at secondary and university levels.

This survey is a preliminary study as far as the Gabonese user profile is concerned. It is not exhaustive. Further quantitative and qualitative research and similar experiments need to be conducted in Gabon with reference to different dictionary users (teachers, children, adolescents and different speech communities), dictionary types, content, presentation of dictionaries, dictionary use, etc.

\section{Bibliography}

Atkins, B.T.S. and K. Varantola. 1998. Language Learners Using Dictionaries: The Final Report on the EURALEX/AILA Research Project on Dictionary Use. Atkins, B.T.S. (Ed.). Using Dictionaries: 21-81. Lexicographica. Series Maior 88. Tübingen: Max Niemeyer.

Béjoint, H. 1981. The Foreign Student's Use of Monolingual English Dictionaries: A Study of Language Needs and Reference Skills. Applied Linguistics 2(3): 207-222.

Bogaards, P. 1988. À propos de l'usage du dictionnaire de langue étrangère. Cahiers de lexicologie 52(1): 131-52.

De Schryver, G.-M. and D.J. Prinsloo. 2000. The Compilation of Electronic Corpora, with Special Reference to the African Languages. Southern African Linguistics and Applied Language Studies 18(1-4): 89-106.

Ekwa Ebanéga, G.-M. 2007. A Microstructural Programme for Dictionaries in Fang. Unpublished D. Litt. Dissertation. Stellenbosch: University of Stellenbosch. 
Gouws, R. H. 1989. Leksikografie. Pretoria: Academica.

Gouws, R.H. 1996. A Sequence for Meeting Lexicographic Needs. Lexicography as a Financial Asset in a Multilingual South Africa: 97-110. Pretoria: Department of Arts, Culture, Science and Technology.

Gouws, R.H. and D.J. Prinsloo. 2005. Principles and Practice of South African Lexicography. Stellenbosch: SUN PReSS.

Hadebe, S. 2004. Improving Dictionary Skills in Ndebele. Lexikos 14: 89-104.

Hartmann, R.R.K. 1989. Sociology of the Dictionary User: Hypotheses and Empirical Studies. Hausmann, F.J. et al. (Eds.). 1989-1991: 102-111.

Hartmann, R.R.K. 1999. Case Study: The Exeter University Survey of Dictionary Use. Hartmann, R.R.K. (Ed.). 1999. Dictionaries and Language Learning: Recommendations, National Reports and Thematic Reports from the TNT Sub-project 9. http://web.fu-berlin.de/elc/tnp1/SP9dossier.doc.

Hartmann, R.R.K. and G. James. 1998. Dictionary of Lexicography. London/New York: Routledge.

Hausmann, F.J. 1989. Die gesellschaftlichen Aufgaben der Lexikographie in Geschichte und Gegenwart. Hausmann, F.J. et al. (Eds.). 1989-1991: 1-19.

Hausmann, F.J. et al. (Eds.). 1989-1991. Wörterbücher. Ein internationales Handbuch zur Lexikographie/Dictionaries. An International Encyclopedia of Lexicography/Dictionnaires. Encyclopédie internationale de lexicographie. Berlin: De Gruyter.

Householder, F.W. and S. Saporta (Eds.). 1962. Problems in Lexicography. Bloomington: Indiana University/The Hague: Mouton.

Idiata, F. 2005. Les langues du Gabon: données en vue d'une classification fondée sur le critère d'intercompréhension. Cape Town: Centre for Advanced Studies of African Society (CASAS).

Mavoungou, P.A. 2001. Macro- and Microstructural Issues in Mazuna Lexicography. Lexikos 11: 122-138.

Mba-Nkoghe, J. 1981. Le Gabon linguistique. Notre librairie. Littérature gabonaise 105: 20-23.

Mickala Manfoumbi, R. 2004. Lexique pove-français/français-pove. Libreville: Éditions RapondaWalker.

Mpofu, N. 2001. Problems of Equivalence in Shona-English Bilingual Dictionaries. Lexikos 11: 242251.

Nesi, H. and R. Haill. 2002. A Study of Dictionary Use by International Students at British University. International Journal of Lexicography 15(4): 277-305.

Nyangone Assam, B. and P.A. Mavoungou. 2000. Lexicography in Gabon: A Survey. Lexikos 10: 252-274.

Tarp, S. 2002. Translation Dictionaries and Bilingual Dictionaries: Two Different Concepts. Journal of Translation Studies 7: 59-84.

Tomaszczyk, J. 1979. Dictionaries: Users and Use. Glottodidactica 12: 103-19.

Whitcut, J. 1986. The Training of Dictionary Users. Ilson, R. (Ed.). Lexicography. An Emerging International Profession: 111-122. Manchester: Manchester University Press.

Wiegand, H.E. 1998. Altes und Neues zur Makrostruktur in alphabetischen Printwörterbüchern. Wiegand, H.E. (Ed.). 1998. Wörterbücher in der Diskussion III. Vorträge aus dem Heidelberger Lexikographischen Kolloquium: 348-372. Lexicographica. Series Maior 84. Tübingen: Max Niemeyer. 